Neurosurg Focus 18 (2):E2, 2005

\title{
Evolution of endovascular therapy for aneurysm treatment
}

\author{
Historical overview
}

\author{
Yassine KanaAn, B.S., David Kaneshiro, B.S., Kenneth Fraser, M.D., \\ DAVID WANG, D.O., AND GIUSEPPE LANZINO, M.D.
}

Departments of Neurosurgery, Radiology, and Neurology, Illinois Neurological Institute, University of Illinois College of Medicine at Peoria, Illinois

\begin{abstract}
The endovascular treatment of intracranial aneurysms has recently become an established therapeutic option. The foundation of this treatment modality was laid by the work done in ground-breaking cases, combined with technological advances since the first half of the 19th century. In this historical overview the authors describe the steps taken by the early pioneers and the results of their work, which was often done under challenging circumstances. The work of these predecessors established the stepping-stones for constant development and refinement for those who have come after them, eventually evolving into the procedures used today. Endovascular treatment of intracranial aneurysms is only possible because of the work of these innovators.
\end{abstract}

KEY WORDS - intracranial aneurysm - endovascular therapy $\quad$ history of neurosurgery

The management of intracranial aneurysms has changed dramatically through time. The science and the art involved have advanced tremendously from its early stages, resulting in ever-improving therapeutic options. Like many advances in medicine and science, the evolution of endovascular therapy to treat intracranial aneurysms is the result of a ceaseless process. Many of the concepts applied to aneurysm treatment today have been around for quite some time. Nevertheless, their safe and widespread clinical application has become possible only in the last few decades, with incredible progress being made in the safety and efficacy of the devices available, better imaging modalities, and improved knowledge of the underlying disease process. Some of the most important steps in this process are summarized in this review.

\section{HISTORY OF ENDOVASCULAR TREATMENT}

The physicians who paved the way for modern-day endovascular coil occlusion of aneurysms began their work in the late 18th century. Several investigators, including Sir E. Herne (as recounted in Ransohoff ${ }^{39}$ ), Phillips ${ }^{37}$ and Velpeau ${ }^{46}$ began experimenting with procedures involving insertion of foreign bodies (needles) into aneurysms to induce thrombosis. Lacking adequate imaging modalities to diagnose small or intracranial aneurysms, these early pioneers concentrated their attention on large lesions of the thoracic or abdominal aorta as well as proximal (extracranial) carotid artery and limb aneurysms. Unpredictable results led to the abandonment of these practices.
Failures of the early attempts to induce aneurysm thrombosis with percutaneous needle insertion led to a renewed interest in medical interventions, the earliest being potassium iodide for syphilitic aneurysms and aneurysm-related pain. The mechanism of action of potassium chloride was thought to be related to the reduction in the pulse and blood pressure, which led to thrombosis. ${ }^{31}$ Other medications included ablation with vinegar, iron perchloride, alcohol, zinc chloride, gelatin, sodium chloride, or ergot salts. ${ }^{41}$ These remedies, which were not based on sound scientific evidence, were used with different degrees of success but failed to find widespread application and were soon abandoned because of inconsistent effects.

Better knowledge of the effects and possible applications of electricity led to the development of electrothrombosis or galvanopuncture. ${ }^{13}$ The mechanism by which electricity produced thrombus formation was largely speculative. Some of the explanations suggested included inflammation, oxidation, or albumin decomposition, the latter being supported by the experiments of Duncan and Fraser $^{13}$ with egg albumin and canine arteries. In the mid-1800s, Cinisellii ${ }^{78}$ published data from 50 cases of aneurysms treated by galvanopuncture, reporting a $50 \%$ success rate and a procedural mortality rate of $14 \%$. By comparison, ligation had a $33 \%$ mortality rate at the time.

In 1864, Moore and Murchison, ${ }^{36}$ inspired by the clinical observation of a fibrin-coated bullet recovered from an autopsy case, postulated that inserting a wire into an aneurysm would provide a much more ideal environment 
for clot formation, as opposed to the insertion of a simple needle. As recounted in 1979 by Schechter ${ }^{41}$, Moore first tested his theory in a thoracic aortic aneurysm, into which 26 yards of coil were introduced. Clinical improvement ensued, with reduction in the size of the aneurysm and a decrease in the pulse rate from 116 to 92 beats per minute. ${ }^{6,36,39}$ Although this patient eventually died of sepsis, at autopsy the coils of wire were filled with "fibrinous coagulum" and were "firmly adherent." As this procedure found widespread application, some of the possible shortand long-term complications became evident. These included increased risk of hemorrhage from subtotal packing and distal embolization of wire or thrombus. ${ }^{41}$

In 1879, Corradi attempted to combine wire insertion and electrothrombosis. This procedure came to be known as the Moore-Corradi method and spread across North America, as detailed by Hunner ${ }^{30}$ and Keen and DaCosta. ${ }^{31}$ The procedure continued to be used with varying degrees of success for several years. In 1912, Finney ${ }^{14}$ reported a case in which he used a 10-foot wire consisting of 75 parts copper to 1000 parts silver that was wound around a wooden spool. He applied a 75-mA current through this apparatus for 1 hour. The mortality rate from this procedure was still considered quite high, and this was attributed by Finney to the severity of the underlying disease. He limited this treatment modality to saccular (as opposed to fusiform) aneurysms. He also foresaw complications of wire migration, emboli formation, ischemia, sepsis, and distal aneurysm formation. The success rate of this combined intervention remained low.

Advances in surgical procedures allowed for a combined approach by which the aneurysm was exposed surgically and wire was inserted through a trocar. This approach was still used by Linton as late as $1951 .{ }^{34} \mathrm{He}$ reported using a combined approach of laparotomy with a trocar in position to visualize his targets, which he packed through multiple sites with up to 965 feet of wire that had an abrasive surface. As explained in Keen and DaCosta, ${ }^{31}$ Linton believed that previous failures resulted from underpacking. Of six patients who were treated in this manner postrupture, three survived less than 1 week, and five lived less than 1.5 years. Of 17 in whom the lesion had not ruptured previously, seven suffered a fatal hemorrhage. The surgical mortality rate for this procedure was $8 \%$.

These early efforts with percutaneous wire insertion culminated with a case reported by Werner, et al., ${ }^{47}$ in 1941, in which a silver wire was used to fill a giant paraclinoid aneurysm via a transorbital approach and then heated to $80^{\circ} \mathrm{C}$ for almost 1 minute. Werner and colleagues reported that this intracranial aneurysm was successfully thrombosed and no longer bled after the conclusion of the operation.

The early attempts and advancements made by these clinicians became the fundamentals on which current endovascular treatment of intracranial aneurysms is based. Although the initial attempts made by these pioneers yielded limited success because tools that could be used to navigate the complex intracranial vasculature and execute the treatment modality were lacking, technological advances and improvements facilitated a shift from the extravascular approach to the more physiological endovascular approach. In the 1960s and early 1970s, the efforts of a number of neurosurgeons and neuroradiologists who desired a therapeutic alternative to conventional surgery made this important shift to catheterization possible. In 1964, Luessenhop and Velasquez ${ }^{35}$ reported safe catheterization of the internal carotid artery by using silastic tubing. These same pioneers described surgically connecting a glass chamber to the patient's external carotid artery and then introducing the tubing into the internal carotid artery to access the intracranial vasculature. In one patient, the neck of a posterior communicating artery aneurysm was selectively occluded by briefly inflating the distal tip of a flow-directed, balloon-tipped catheter. By proving the feasibility of using selective distal intracranial catheterization to treat aneurysms, this ground-breaking method shifted the focus from the extravascular to the endovascular approach.

Superselective catheterization with minimal vessel damage, an additional endovascular breakthrough achieved in 1966, was accomplished by Frei, et al., ${ }^{16}$ with the creation of the paraoperational device catheter. To ease the difficulty of directing the paraoperational device catheter through the tortuosities of the intracranial vasculature, Frei and colleagues designed a catheter tip with an attached micromagnet. Therefore, an external magnetic field could be used to control the intravascular catheter. This magnetic guidance model became well liked by clinical researchers. ${ }^{1-3,12,28,43,49,50}$

The development of magnetic technology to aid navigation of endovascular devices when treating intracranial aneurysms led to other clinical approaches in their management. Yaşargil, ${ }^{49}$ who was equally skilled in cerebral angiographic and stereotactic modalities, imagined harnessing magnetic potential to treat aneurysms in another way. He believed that aneurysm thrombosis can be achieved by introducing iron particles into the intracranial vasculature and using magnetically charged probes to direct the particles within the lesion. Although unable to perform clinical experimentation with this approach, Yaşargil conveyed his vision of magnetically directed embolization to Robert Rand. A pupil of Rand, John Alksne, pursued this method with some colleagues and conducted extensive clinical investigations. They induced a more stable, well-formed clot than that induced by electrothrombosis by combining intracranial catheterization and magnetically directed embolization. ${ }^{1-3,43}$ As in Yaşargil's original proposal, intraaneurysm thrombosis was achieved with iron particles ${ }^{2}$ or in a liquid acrylic mixture suspension. ${ }^{3}$ In addition, in 1974 Hilal, et al., ${ }^{28}$ experimented with magnetically directed catheters in combination with electrothrombosis to obliterate intracranial aneurysms.

Further improvements in the endovascular arena took a new direction, away from stereotactically placed magnets and magnet-tipped catheters to balloon-tipped microcatheters. This new direction followed the introduction of the Fogarty catheter by T. J. Fogarty and colleagues..$^{15}$ This device was developed for the extraction of arterial emboli and thrombi, and led to advancements in the feasibility of balloon catheters. ${ }^{5,32,38}$ The article on balloon catheterization and occlusion published by Serbinenko ${ }^{42}$ in 1974 detailed an influential advancement that became a conventional treatment for intracranial aneurysms. ${ }^{45,48}$ Soon after the development of endovascular detachable balloon embolization therapy, a number of publications describing the outcome of this method in treating various cere- 
brovascular lesions, including intracranial aneurysms,

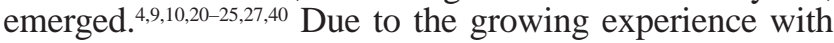
the detachable balloon embolization approach, a number of problems with this method became evident.

First, access to the aneurysm was challenging because a guidewire could not be used during catheterization. Second, once the lesion was finally reached, the balloon did not achieve full occlusion of the aneurysm because the device was round or oval. In addition, balloons that do not fully conform to the irregular dimensions of the aneurysm sac have been reported to undergo a "water-hammer effect" from pulsating arterial blood on the balloon-aneurysm complex; this facilitates recanalization, enlargement, or delayed rupture of the intracranial aneurysm. ${ }^{33}$ Another major drawback to the balloon occlusion procedure is that these devices will slowly deflate over time if they are not filled with nonsolidifying substances. Although parent artery occlusion can still be performed despite this disadvantage, balloon occlusion of the aneurysm sac has been largely abandoned in favor of more novel techniques.

The next endovascular approach designed for the selective occlusion of aneurysms was the coil. Modern metallic coils had been available for endovascular arterial occlusion and embolization since $1975,{ }^{17}$ although the use of coils specifically for the treatment of intracranial aneurysms did not occur until the very late 1980s. ${ }^{29}$ Subsequently, Dowd, et al., ${ }^{11}$ and Higashida, et al., ${ }^{26}$ described their use of endovascular coil embolization with "pushable" platinum coils. One disadvantage to this method was the inability to retrieve the coil after placement.

The technological ingenuity and determination of Guido Guglielmi, a neurosurgeon from Italy, led to further refinements in the metallic coil, eventually leading to the development of the detachable coil. While experimenting in the early 1980s and eventually with the aid of Ivan Sepet$\mathrm{ka}$, an engineer at Target Therapeutics, Inc., he combined endovascular electrolysis with electrothrombosis to develop the currently used Guglielmi detachable coil (Boston Scientific/Target Therapeutics, Fremont, CA). ${ }^{18,19,44}$

The bold efforts of these pioneering surgeons and physicians have built the framework of knowledge upon which current endovascular therapies are based. Trial, error, and ingenuity have advanced our abilities to treat intracranial aneurysms safely and effectively. Standing on the shoulders of such giants, we can see where they have led us and, we hope, see a path toward improving on what is, even now, a wonder of modern medical science.

\section{References}

1. Alksne JF: Magnetically controlled intravascular catheter. Surgery 64:339-345, 1968

2. Alksne JF: Stereotactic thrombosis of intracranial aneurysms. $\mathbf{N}$ Engl J Med 284:171-174, 1971

3. Alksne JF, Smith RW: Iron-acrylic compound for stereotaxic aneurysm thrombosis. J Neurosurg 47:137-141, 1977

4. Berenstein A, Ransohoff J, Kupersmith M, et al: Transvascular treatment of giant aneurysms of the cavernous carotid and vertebral arteries. Functional investigation and embolization. Surg Neurol 21:3-12, 1984

5. Cares HL, Hale JR, Montgomery DB, et al: Laboratory experience with a magnetically guided intravascular catheter system. J Neurosurg 38:145-154, 1973
6. Christian HA: Aneurysms of the thoracic aorta treated by wiring. Boston Med Surg J 166:122-127, 1912

7. Ciniselli L: [Observation on aortic aneurysms treated with electropuncture.] Adunanze dell' Accademia 12:418-430, 1872 (Ita)

8. Ciniselli L: [Observations about electropuncture on the treatment of aneurysms.] Gazzetta Medica di Milano 6:9-14, 1847 (Ita)

9. Debrun G, Fox A, Drake C, et al: Giant unclippable aneurysms: treatment with detachable balloons. AJNR 2:167-173, 1981

10. Debrun G, Lacour P, Caron JP, et al: Detachable balloon and calibrated-leak balloon techniques in the treatment of cerebral vascular lesions. J Neurosurg 49:635-649, 1978

11. Dowd CF, Halbach VV, Higashida RT, et al: Endovascular coil embolization of unusual posterior inferior cerebellar artery aneurysms. Neurosurgery 27:954-961, 1990

12. Driller J, Hilal SK, Michelsen WJ, et al: Development and use of the POD catheter in the cerebral vascular system. Med Res Eng 8:11-16, 1969

13. Duncan J, Fraser TR: On the treatment of aneurism by electrolysis. With an account of an investigation into the action of galvanism on blood and on albuminous fluids. Medico-Chir Soc Edinb Med J 13:101-120, 1867

14. Finney JMT: The wiring of otherwise inoperable aneurysms. With the report of cases. Ann Surg 55:661-681, 1912

15. Fogarty TJ, Cranley JJ, Krause RJ, et al: A method for extraction of arterial emboli and thrombi. Surg Gynecol Obstet 116: 241-244, 1963

16. Frei EH, Driller J, Neufeld HN, et al: The POD and its applications. Med Res Eng 5:11-18, 1966

17. Gianturco C, Anderson JH, Wallace S: Mechanical devices for arterial occlusion. Am J Roentgenol Radium Ther Nucl Med 124:428-435, 1975

18. Guglielmi G, Viñuela F, Dion J, et al: Electrothrombosis of saccular aneurysms via endovascular approach. Part 2: preliminary clinical experience. J Neurosurg 75:8-14, 1991

19. Guglielmi G, Viñuela F, Sepetka I, et al: Electrothrombosis of saccular aneurysms via endovascular approach. Part 1: electrochemical basis, technique, and experimental results. J Neurosurg 75:1-7, 1991

20. Hieshima GB, Higashida RT, Halbach VV, et al: Intravascular balloon embolization of a carotid-ophthalmic artery aneurysm with preservation of the parent vessel. AJNR 7:916-918, 1986

21. Hieshima GB, Higashida RT, Wapenski J, et al: Balloon embolization of a large distal basilar artery aneurysm. Case report. J Neurosurg 65:413-416, 1986

22. Hieshima GB, Higashida RT, Wapenski J, et al: Intravascular balloon embolization of a large mid-basilar artery aneurysm. Case report. J Neurosurg 66:124-127, 1987

23. Higashida RT, Halbach VV, Barnwell SL, et al: Treatment of intracranial aneurysms with preservation of the parent vessel: results of percutaneous balloon embolization in 84 patients. AJNR 11:633-640, 1990

24. Higashida RT, Halbach VV, Cahan LD, et al: Detachable balloon embolization therapy of posterior circulation intracranial aneurysms. J Neurosurg 71:512-519, 1989

25. Higashida RT, Halbach VV, Dowd C, et al: Endovascular detachable balloon embolization therapy of cavernous carotid artery aneurysms: results in 87 cases. J Neurosurg 72:857-863, 1990

26. Higashida RT, Halbach VV, Dowd CF, et al: Interventional neurovascular treatment of a giant intracranial aneurysm using platinum microcoils. Surg Neurol 35:64-68, 1991

27. Higashida RT, Halbach VV, Dowd CF, et al: Intracranial aneurysms: interventional neurovascular treatment with detachable balloons-results in 215 cases. Radiology 178:663-670, 1991

28. Hilal SK, Michelsen WJ, Driller J, et al: Magnetically guided 
devices for vascular exploration and treatment. Radiology 113: 529-540, 1974

29. Hilal SK, Solomon RA: Endovascular treatment of aneurysms with coils. J Neurosurg 76:337-339, 1992

30. Hunner GL: Aneurism of the aorta treated by the insertion of a permanent wire and galvanism (Moore-Corradi method). Bull Johns Hopkins Hosp 11:263-279, 1900

31. Keen WW, DaCosta JC (eds): Surgery, Its Principles and Practice. Philadelphia: WB Saunders, 1916

32. Kessler LA, Wholey MH: Internal carotid occlusion for treatment of intracranial aneurysms. A new percutaneous technique. Radiology 95:581-583, 1970

33. Kwan ES, Heilman CB, Shucart WA, et al: Enlargement of basilar artery aneurysms following balloon occlusion"water-hammer effect." Report of two cases. J Neurosurg 75: 963-968, 1991

34. LINTON RR: Intrasaccular wiring of abdominal arteriosclerotic aortic aneurysms by the "pack" method. Angiology 2: 485-498, 1951

35. Luessenhop AJ, Velasquez AC: Observations on the tolerance of the intracranial arteries to catheterization. J Neurosurg 21: 85-91, 1964

36. Moore $\mathrm{CH}$, Murchison $\mathrm{C}$ : On a new method of procuring the consolidation of fibrin in certain incurable aneurysms: with the report of a case in which an aneurysm of the ascending aorta was treated by the insertion of wire. Med Chir Trans 47:129, 1864

37. Phillips B: A Series of Experiments Performed for the Purpose of Shewing That Arteries may be Obliterated Without Ligature, Compression, or the Knife. London: Longman, 1832

38. Prolo DJ, Hanbery JW: Intraluminal occlusion of a carotid-cavernous sinus fistula with a balloon catheter. Technical note. J Neurosurg 35:237-242, 1971

39. Ransohoff J: A case of aortic aneurism treated by the insertion of wire. JAMA 7:481-485, 1886
40. Romodanov AP, Shcheglov VI: Intravascular occlusion of saccular aneurysms of the cerebral arteries by means of a detachable balloon catheter, in Krayenbühl H (ed): Advances and Technical Standards in Neurosurgery. New York: SpringerVerlag, 1982, Vol 9, pp 25-49

41. Schechter DC: Flashbacks: electrical treatment of aneurysms. Pacing Clin Electrophysiol 2:234-245, 1979

42. Serbinenko FA: Balloon catheterization and occlusion of major cerebral vessels. J Neurosurg 41:125-145, 1974

43. Smith RW, Alksne JF: Stereotaxic thrombosis of inaccessible intracranial aneurysms. J Neurosurg 47:833-839, 1977

44. Target Therapeutics: Target Therapeutics: History of the GDC. Fremont, CA: Target Therapeutics, 1995

45. Teitelbaum GP, Larsen DW, Zelman V, et al: A tribute to Dr. Fedor A. Serbinenko, founder of endovascular neurosurgery. Neurosurgery 46:462-470, 2000

46. Velpeau A: [Memoir on the piqure or the acupuncture of arteries in the treatment of aneurysms.] Gaz Med Paris 2:1-4, 1831 (Fre)

47. Werner SC, Blakemore AH, King BG: Aneurysm of the internal carotid artery within the skull. JAMA 116:578-582, 1941

48. Wolpert SM: In re: Serbinenko FA. Balloon catheterization and occlusion of major cerebral vessels. J Neurosurg 1974;41:974. AJNR 21:1359-1360, 2000

49. Yaşargil MG: A legacy of microneurosurgery: memoirs, lessons, and axioms. Neurosurgery 45:1025-1092, 1999

50. Yodh SB, Pierce NT, Weggel RJ, et al: A new magnet system for "intravascular navigation." Med Biol Eng 6:143-147, 1968

Manuscript received December 17, 2004

Accepted in final form January 6, 2005.

Address reprint requests to: Giuseppe Lanzino, M.D., Department of Neurosurgery, 530 NE Glen Oak Avenue, Peoria, Illinois 61637. email: lanzino@uic.edu. 